Volume 11, Issue 12, December 2020, pp. 143-148. Article ID: IJM_11_12_016

Available online at http://iaeme.com/Home/issue/IJM?Volume $=11 \&$ Issue $=\overline{1} 2$

Journal Impact Factor (2020): 10.1471 (Calculated by GISI) www.jifactor.com

ISSN Print: 0976-6502 and ISSN Online: 0976-6510

DOI: 10.34218/IJM.11.12.2020.016

(c) IAEME Publication

Scopus Indexed

\title{
LANGUAGE GAME: LUDWIG WITTGENSTEIN
}

\author{
Dipankar Das* \\ Ex-Student (2017-19), Department of Philosophy, \\ Gauhati University, Assam, India \\ Rituparna Neog \\ Ex-Student (2016-18), Department of Philosophy, \\ Gauhati University, Assam, India \\ *Corresponding Author
}

\begin{abstract}
The term 'language game' was first used in linguistic philosophy at $20^{\text {th }}$ century. Wittgenstein's theory of language game gives outstanding contribution to the analytical philosophy. He describes mainly Seventy three (73) examples of language games in his Brown book (1938). Every language game described predicted situation. Further analysis of language game elaborated in his two main work- "Philosophical Investigation" and "On Certainty". According to him, language is a kind of game, which we play through language. Through language we can describe the picture of the world, which is elaborated in his 'Tractatus', but later in his Philosophical Investigation, he tried to analyse 'language has no singles essence'. Language is a kind of game, and words or sentences are the tools of language. In Philosophical Investigation, he rejected three assumptions, i.e. language is used for presenting of facts in one purpose; through picturing the sentence acquires meaning in one way; in logical calculus that language has a clear and distinct structure. The major objective of this paper is to interpret the Wittgenstein's view of 'Language game'.
\end{abstract}

Key words: Language game, Tractatus, Brown book, Philosophical Investigation, Analytic Philosophy.

Cite this Article: Dipankar Das and Rituparna Neog, Language Game: Ludwig Wittgenstein, International Journal of Management, 11(12), 2020, pp 143-148.

http://iaeme.com/Home/issue/IJM?Volume=11\&Issue=12

\section{INTRODUCTION}

In his book 'Logical Investigation', Wittgenstein says, language is not one logical structure but it is many. And language has no single essence because language is the sum of uses which has own logic and logical structure. The relation between sound and thing does not depend on proposition or a living order. But the meaning of one statement implies uses of different language which come through effect of many sources of language. "The term language game 
is meant to bring into prominence the fact that the speaking of language is part of an activity, or of a form of life." (Philosophical Investigation: 23). So, Wittgenstein has given a motto, 'do not look for meaning, looks for use.' Based on this theory, Wittgenstein initiated two another famous theories, viz, "Use theory of meaning" and "the theory of language game." Through language games, Wittgenstein teach us that utterance must be viewed in terms of the activity where they are used. This notion of language game was used by Wittgenstein in a way which took this property of language use as fundamental.

Wittgenstein's 'Logical Investigation' rest on the central theme of the concept of meaning. And he asserts that to have the same meaning of word does not imply to use the same word. Bishop in a game of chess which meaning is not achieved by finding out the material of which piece is make. Bishop is not considered as the name of a piece or ivory and it can be made with the Bishop and the rules which is governed by Bishop, but it is a function into a context of rules. An example can be given here, the word 'love' of a game like long tennis, which is used as zero but has nothing to do with the emotion. Intention is possible to define variously, Disposition, decision, prediction, desire, purpose or all motives are signified. And the grammar proposes that plan of functions as an auxiliary than as a verb to completed it something is needed. It is also similar with the variable that may be furnished by the object of intention. Wittgenstein compared language with the toolbox. In a toolbox, there may be many tools like square, hammer, gluepot. Wittgenstein assert multiplicity of language game, which refers, word have a multiplicity of different uses. He explained it clearly through an example of the Builder and his assistant of language game. This example is a primitive form of language, which he called language game. This kind of primitive forms of thinking come to light less bewildered. Though he did not give more focus on the complex natural language. But according to him complex natural language is not completely different from this simple primitive forms. Complex natural language is also help to better understanding of language function.

\section{OBJECTIVES}

The primary objective of this article is to study about:

- To interpret the Ludwig Wittgenstein's notion of language game.

- To give a brief explanation of different moves or an activity of a game and the characteristics of a language game.

- Why we cannot define language game as a concrete idea.

\section{METHODOLOGY}

Here, in this article, the concept based analytical methodology is applied for study. The concept based analytical methodology will be based on secondary sources which are examined through the process of analysis. The secondary data is collected from various books, documents and journals etc.

\section{RESULT AND DISCUSSION}

For Wittgenstein, the language must be use in a proper way, then we get the real meaning. In the case of playing a game there is some rules, which we must obey as well as in the use of language, there is also some rules which are necessary to follow. Here we are going to discuss, the characterizations of language game, the moves of a game, the games and language and family resemblances etc. 


\subsection{Characterization of Language Game}

Wittgenstein mainly concerned with those game which are associated with the use of a language. The central aim of the game is realization of a language where game was initiated corresponding intention by the interest of the participant. Social intention in a wide sense, mainly associated with use of a language. As separated from social interaction there can be viewed as a formulation of the question 'what is communication'. The question is not an easiest task to means. Allwood discuss about the issues.

According to Allwood, there are three levels of 'sender activity'. Such as follows(i)Indication: Information transmitted by the sender or obtainable for interpretation.

(ii)Display: Behavior displays by the sender intentionally.

(iii)Signaling: The behavior of the sender has the intention that will be realize the receiver, what the intention is.

Mentioned above the three notion, Allwood defines the receiver may interpret any behavior among the three notion of levels. Nevertheless, the intention of the sender. Accordingly, this may give rise to a mistake. Now, if the sender signal behavior occurs than communication of sender and receiver, is perceived as in the fullest sense. From the above levels of communicative games, we define as the rules that if requires at least behavior display by the all participants.

A communicative game requires the rules that the participants signal behavior that's why it is different from a language game. The action in a language game may have a symbolic quality. A game means a set of convention when the demand of symbol taken as a whole. Thus, language game formally defines not as a concrete structure but as an abstract, where parties involved with the reference to a collection of rules. Each and every game put in a certain frame. Therefore, if we realize a language game that it is accessible which are associated with an intention of the game as a part of initiator. If it views from another frame of other interactant, chose to interpret the initiative distinctly. This results in a mistake on some levels. Although if this happens on a low level it may pass unnoticed.

\subsubsection{The moves of a game}

According to Wittgenstein, a language game can be described as consisting some sequence of moves. The rules of game include the moves of an action. These are typically actions, which are expected by the participants of the game, so that if a move is never made, participants will feel that something is missing. Sacks in his definition of the adjacency pair (the definition is quoted from Goffman 1976), described this property very well:

"The first pair part establishes a conditional relevance upon anything that occurs in the slot that follows; whatever comes to be said there will be inspected to see how it might serve as an answer, and if nothing is said, then the resulting silence will be taken as notable- a rejoinder in its own right, a silence to be heard."

Here this definition captures extremely well the property of a move as something which is expected to occur by participants. We may look at the question-answer structure as an example of moves within a language game. Generally, the usual kind of game is called "information-seeking", and it is a name which reflects the usual purpose of a question. The moves are simply, in rough terms:

P1 asks a question (according to rules specifying a question).

P2 answer the question (according to rules specifying what is an answer to a particular question).

Here, the rules for the moves of a game may be very complex. We will not at this moment deal with the rules of any game in detail. The most important issue is that, how many moves 
we can expect in a language game. Is there is a specified number of moves, which is the same in all games on a certain level of description? This should be taken as an empirical question, which is given in the account of language game above. Again, the question is that, what criteria should be used to determine what is move. One possible criterion is that, actions which are expected by participants. If we look at a simple greeting ceremony:

A: Hi.

B: Hi.

(A notices B; s response)

Perhaps, one could say that there are three actions involved. After the first one, it is certainly the case that A expects B to answer his greeting. However, the question is that, if the third action can be described as expected by B in the same sense of 'expect'. According to this criterion, if it cannot, there should be only two moves in a greeting game of this type. (Severinson Eklundh \& Linell 1983).

'Anticipation' is a kind of criterion, which is slightly different. For instance, one could design an experiment, where subjects were asked to predict other's action in a game. Actions which are predictable in a game regardless of the identity of participants are probably very likely candidates for moves in the game. We can say that, a move is an action which is somehow perceived as constituting an understanding of the overall purpose of the game. We should have in mind that the move status of an action is a game is a problem which deserves empirical study.

\subsection{Family Resemblances}

Wittgenstein's idea of 'family resemblance' is integral part of language game. According to this idea, different things is thought to be connected by one necessary common character which is a series of overlapping similarities, where no one thing has common feature to all of things. Wittgenstein given an example through he described the concept clearly. Example is as follows-

Item 1: $\mathrm{ABCD}$

Item 2: BCDE

Item 3: $\mathrm{CDEF}$

Item 4: DEFG

Item 5: EFGH

Mentioned above there have total five items. To define characteristics of every items had taken Alphabet ABC. There may be similarities between the item 1 and the item 2 (BCD), but there have no similarities between the item 1 and the 5 . The item 2 has some similarity with the item 5 (E). The item 3 has some similarities with the item 5 (EF). Lastly the item 4 also has some similarities with 5 (EFG). If we look at 5 items, then there may have similarities of criss-crossing. Though some items are not similar but some relations are common. Such network of similarities, Wittgenstein called 'family resemblance'. He describes, "Consider for example the proceeding, that we call 'game'. I mean 'Board games', 'Ball games', 'Olympic games' and so on. What is common to them all? -Do not say: "There must be something common, or they would not be called 'games'- but looks and see whether there is anything common to all. For it you look at them, you will not see something that is common to all- but similarities, relationship, and a whole series of them at that... we see a complicated network of similarities overlapping and criss-crossing: Sometimes overall similarities, sometimes similarities of detail... I can think no better expression to characterize these similarities then 'family resemblances... And I shall say: games forma family'." (Philosophical Investigation: 66-67). 
So, Wittgenstein said that, we can see resemblances or similarities of different kinds of games, but cannot find any common feature. According to Wittgenstein, if we compare one game with another game then there must have some similarities, on the other hand it may not have any similarities when we see from other side. So according to him, through family resemblances we can describe the meaning of a word. He called language is that, produces something common to all. There have no one thing in common for all, which makes us to use the same word for all in same phenomena. But it may be related to one another in many different ways, because of their relationship. This relationship, Wittgenstein called 'language' (in his famous work 'Logical Investigation').

\subsection{Games and Language}

The term 'game' is often used metaphorically about language in everyday life. The activities like political debates, we talk about speaking as 'playing with words' and word game is often used. The word game can be used in a variety of several ways. The question is that, what aspects of language are covered by the game metaphor? We look briefly at the ways in which we use the words 'game' and 'play' in everyday language. We use these words about things as different as sounds (like piano play), to refer to athletic activities, dramatic art, children's play etc. In a present time, it is not necessary, nor possible to give a comprehensive analysis of the notion of game. There are some important components which seem to be present in many of the activities we call game or play, i.e. the Swedish word 'spel', as well as the German word 'spiel', which covers both game and play in English.

Wittgenstein introduced 'language game' in his latter works (about language), where he discusses various aspects language use. He used language game in two ways- 'to refer to a primitive language' and 'to denote different kinds of language use in ordinary language'. In primitive language there is- a systematic sequencing of actions; the actions are rule governed; they take place in a restricted world or context. According to Wittgenstein, our own languages have features which are very similar to the primitive languages. Only they are much more complex, and we use language in a vast number of different ways. And on the other hand, in other class of language games, that is the list of 'natural' use of language. This view amounts to an analysis of different kinds of language use as structured according to the general format involving rules for actions performed by participants in an activity. We can look at these language uses in the same way as the primitive forms of language, through this reflection children can learn language.

\section{CONCLUSION}

Wittgenstein focused how a concept of language game can be used as a basic for the purpose of analyzing language. To bring into prominence of the fact that the speaking of language is part of an activity or a form of life. He says that, philosophical problem is not similar with the mathematical language, because in linguistic confusion is the result of philosophical problem. Philosophical problem arises when language goes on holiday. The concept originated from out of the ordinary use of the language. He also says, looking into working of our language solved by the philosophical problem. Problems are solved by only arranging methodology that about what we always known, not by giving any new information. He asserts, significance of linguistic usage depends on the condition of life in their approach. Anything about language means 'participants in forms of life'. According to him, forms of life means a context of life, where people are bound with each other. He compresses language with game, because game is governed by some rules, similarly, functions of language is regulated by some rules. How can we use language, what kinds of language we use, that all functions are governed by 'obeying rules.' For him, language is not considered as similar thing, it is the 
sum total of different activities. We use language to describe the appearance of something, for best wishes, for explaining emotion etc. These kinds of activities are similar with language game and they are sum of activities. We can use language in different ways, which are called by Wittgenstein 'multiplicity of language'. So, he introduces the term 'language game', which meant to bring prominence the fact speaking of language is part of an activity or a form of life (Philosophical Investigation:23). Hence, Wittgenstein assert adopting of definite methodology through which we can solved the philosophical problem, because philosophical problems are not empirical problems. These problems are solved by arranging knowledge which we have always, not by giving information.

\section{REFERENCES}

[1] Eklundh, Kerstin Severinson. (1983). The Notion of Language Game- A Natural Unit of Dialogue and Discourse. University of Linkoping Studies in Communication.

[2] Fann, KT. (1969). Wittgenstein's Conception of Philosophy. California: University of California Press.

[3] Finch, Henry LeRoy (1979). Wittgenstein- The Early Philosophy: An exposition of "Tractatus", New York: Humanities Press.

[4] Kuhn, Thomas S. (1970). The Structure of Scientific Revolutions, The University of Chicago Press.

[5] Pitcher, George. (1964). The Philosophy of Wittgenstein. New Delhi: Prentice- Hall of India Private Ltd.

[6] Wittgenstein, Ludwig. (1961). Tractatus Logco-Philosophicus. London: Routledge \& Kegan Paul.

[7] Stern, David G. (1995). Wittgenstein on Mind and Language. Oxford: Oxford University Press. 